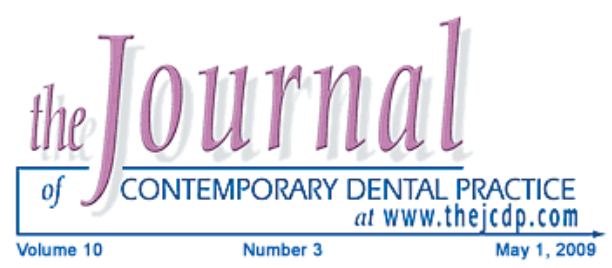

\title{
The Effect of Pre-cooling the Injection Site on Pediatric Pain Perception during the Administration of Local Anesthesia
}

\author{
Naser Asl Aminabadi, DDS, MSc;
}

Ramin Mostofi Zadeh Farahani, DDS

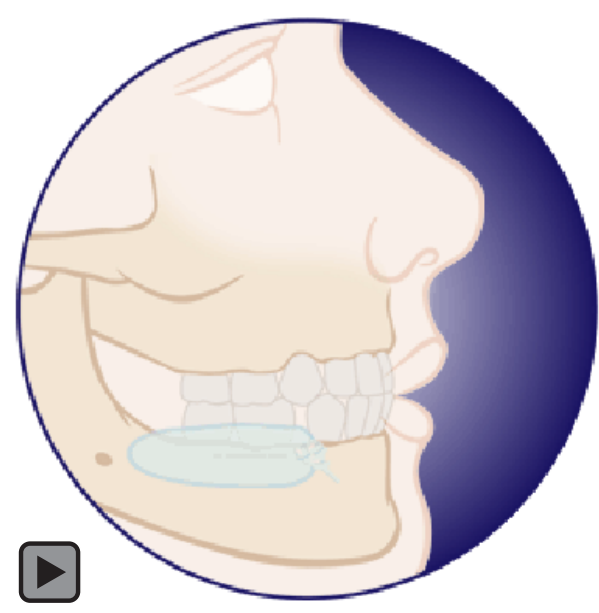

Abstract

Aim: The aim of the study was to evaluate the effect of cooling the soft tissue of injection sites on the pain perceptions of pediatric patients during the administration of local anesthesia for routine dental procedures.

Methods and Materials: A total of 160 children aged 5-6 years were included in the present study. On a random basis, the subjects were allocated to the without ice pretreatment (WIP) group (topical anesthesia + counterstimulation + distraction) or the ice pretreatment (IP) group (cooling + topical anesthesia + counterstimulation + distraction). During the administration of an inferior alveolar nerve block, the children's behavior was assessed using the sound, eye, and motor (SEM) scale. The statistical analysis of data was performed based on the analysis of variance (ANOVA).

Results: There were no significant differences within the groups between the values of the sound, eye, and motor components for either the WIP or the IP groups $(P>0.05)$. All three components of the SEM in the IP group were consistently lower than the WIP group $(P<0.05)$. Moreover, the SEM value for the WIP group surpassed the IP group $(P<0.05)$.

Conclusions: Cooling the site of infiltration block prior to the injection of local anesthesia significantly reduced the pain perceived during injection of local anesthetic agent in pediatric patients.

(c) Seer Publishing 
Clinical Significance: Pre-cooling of the soft tissues of an injection site prior to the administration of a local anesthetic can minimize the discomfort and anxiety associated with the injection procedure and facilitates the management of pediatric patients during this phase of a dental procedure.

Keywords: Intraoral infiltration, pain perception, local cooling

Citation: Aminabadi NA, Farahani RMZ. The Effect of Pre-cooling the Injection Site on Pediatric Pain Perception during the Administration of Local Anesthesia. J Contemp Dent Pract 2009 May; (10)3:043-050.

\section{Introduction}

Anxiety is still considered a serious patientcentered challenge in modern dental practice. ${ }^{1}$ Paradoxically, the administration of the anesthetic agent is the most painful part of most dental procedures. ${ }^{2}$ Pain association quickly develops into avoidance behaviors which may in turn affect prospective therapeutic procedures. ${ }^{3.5}$ The role of anxiety is even more profound in pediatric patients. Effective pain control during dental treatment is the cornerstone of pediatric behavior management. Procedures performed under local anesthesia require patient co-operation to be successful. ${ }^{6}$

Several methods have been suggested to reduce pain caused by the administration of local anesthetic agents. These include the following:

- Application of topical analgesics such as amethocaine $^{7}$

- Distraction techniques ${ }^{8,9}$

- Counter irritation ${ }^{10}$

- Warming the anesthetic agents ${ }^{11}$

- Adjusting the rate of infiltration ${ }^{12}$ by reducing the speed of the injection

- Buffering the local anesthetic agent ${ }^{13-18}$

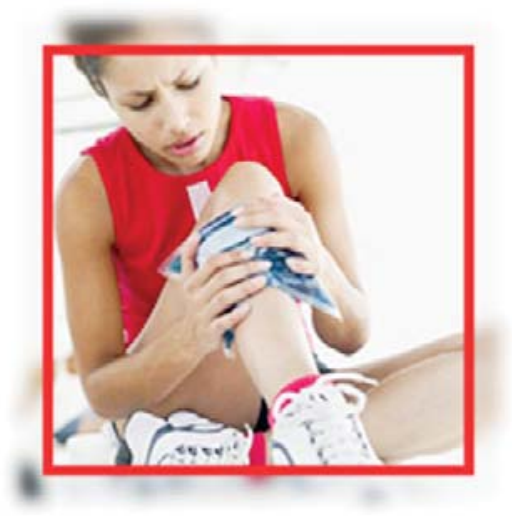

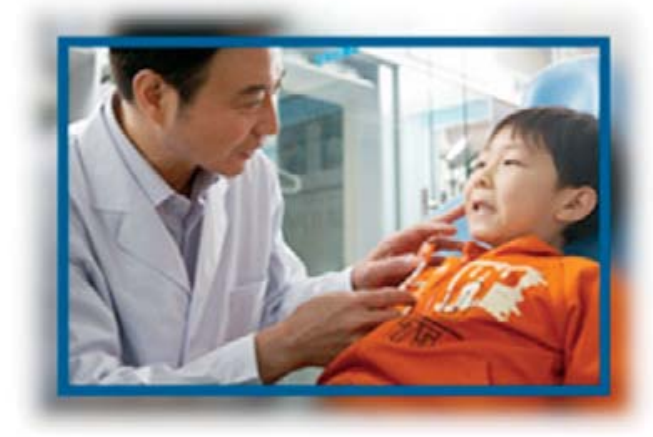

Cooling injured tissues has a long-standing history in medicine. Local external cooling for pain relief has been used for treating sprains, burns, fractures, bruising, and insect bites.

Regional skin cooling to reduce pain from sports injuries is commonplace. ${ }^{19,20}$ A number of studies have shown the benefits of postoperative skin cooling to reduce wound pain and edema. ${ }^{21-24}$ The potential for pre-operative use of these cooling techniques is promising. ${ }^{25}$ Ethyl chloride has been widely used for pre-injection anesthesia as well as for pain control in minor surgical procedures, minor sports injuries, and myofacial pain. ${ }^{26,27}$ However, Waibel and Katial ${ }^{28}$ reported despite improved pain scores with ethyl chloride in skin tests, the results were not statistically significant. Furthermore, although incidences are rare, there are additional reported health hazards due to the inhalation of or continuous exposure to vapor coolant spray such as frostbite, contact dermatitis, and death. ${ }^{29-31}$ Ice has been also used to control musculoskeletal pain, discomfort from a local anesthetic injection, postoperative pain, and prevention of edema. ${ }^{32-35}$

However, it would appear only one study has investigated the effects of local mucosal cooling prior to the infiltration of local anesthesia on nociceptive activity in oro-dental procedures. ${ }^{36}$ 
The investigators of the present study hypothesize local cooling of the soft tissue at an injection site through the use of ice prior to the administration of local anesthesia may lead to decreased pain perception during the injection procedure.

Therefore, the aim of the study was to evaluate the effect of cooling the soft tissue of injection sites on the pain perceptions of pediatric patients during the administration of local anesthesia for routine dental procedures.

\section{Methods and Materials}

\section{Study Population}

A total of 160 children aged 5-6 years were included in the present randomized clinical trial. The subjects presented at the Department of Pedodontics, School of Dentistry at the Tabriz University of Medical Sciences in Tabriz, East Azerbaijan, Iran for the treatment of carious primary teeth. The selected subjects were in complete physical and mental health without any confounding medical history. The targeted teeth for the study were carious mandibular primary first or second molars without pulpal involvement.

The following criteria were considered for inclusion of a patient in the study:

- Existence of carious primary mandibular molars necessitating the use of an inferior alveolar nerve block

- No history of post-traumatic stress disorders or specific phobia related to dental settings

- No history of unpleasant experiences in medical settings

- No previous experience with intraoral injections

- No history of pain secondary to pulpitis favoring a biased context due to special pain syndromes such as hyperalgesia or allodynia

- No allergy to lidocaine

- Patient was cooperative

The study procedure as well as probable risks and discomforts were explained to the parents or legal guardians of the patients. The study procedure was approved by the Research and Ethics Committees of Tabriz University of Medical Sciences.

\section{Treatment Procedure}

During the first therapeutic session fluoride therapy was performed for the subjects and only cooperative children (Frankel's Class III or IV) were included in the study procedure.

The 160 patients selected for the study were assigned to one of two study groups by the admitting dentist who drew one card for each patient from a box containing 160 folded cards (80 marked Control and 80 marked Study). The patient was assigned to the corresponding group listed on the card prior to seating in a treatment room. Concealment of the group assignment was maintained until the statistical analysis was completed.

The treatment procedure for both the study and control groups began with the application of a topical anesthetic agent (Benzocaine ${ }^{\circledR}$, Dentsply, York, UK) over dried mucosa for 1 minute using a cotton applicator. Patients in the study group received an ice pretreatment (IP) of the soft tissues of the injection site for 2 minutes using a tube of ice. ${ }^{37,38}$ The control group, without ice pretreatment (WIP), only received the application of topical anesthetic. The ice tube was made by filling the small finger of a latex glove with water; knotting the open end then cutting away the rest of the glove and placing the water-filled portion in the freezer (Figure 1).

A standard inferior alveolar nerve block injection technique was applied using counterstimulation and distraction for both the control and study groups. The counterstimulation method used for the study group was the ice pretreatment of the injection site. As for the control group, only

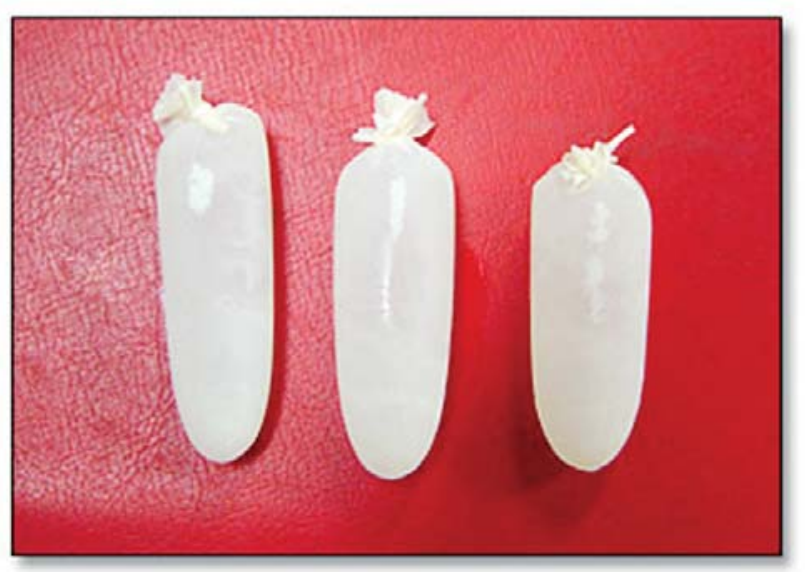

Figure 1. The ice tube prepared from the small finger portion of latex gloves. 
a thumb-finger grasp of the ascending ramus of the mandible with gentle pressure while vibrating the soft tissues adjacent to the intraoral injection site was used as counterstimulation. The range of vibration movement was approximately $1 \mathrm{~mm}$ (short back-and-forth as well as up-and-down movements), and the frequency of vibration was 1 cycle/second.

The technique used for distraction was to ask the subjects in a controlled monotone voice to alternately raise their right and left legs in turn.

The technique used for administration of the anesthetic involved the gradual injection of $1 \mathrm{ml}$ of anesthetic agent (Lidocaine 2\%, Epinephrine 1/100000) using a short needle (length: $32 \mathrm{~mm}$, gauge: 27) over a period of 1 minute following syringe aspiration.

The same procedure for the administration of local anesthesia in the WIP group (control) was performed by the same pedodontist used for the IP group.

Subsequently, all carious lesions were removed using a high-speed handpiece to create standard Class II cavity preparations. After removal of any remaining affected dentin and refinement of the cavity walls, matrix bands and wooden wedges were placed and the teeth were restored with amalgam restorations.

Assessment of Subject Behavior A second dentist, blind to the study procedure, assessed patient behavior during injections using the SEM scale. The SEM scale is described in Table 1.

The assessment criteria of the SEM scale are based on three types of data, namely child sounds (verbalizations), eye signs, and body movements. A third investigator randomly performed the SEM evaluation along with the second investigator to allow for the assessment of inter-examiner agreement of the data.

\section{Statistical Analysis}

All quantitative data are presented as means. The statistical analysis of data was performed based on the analysis of variance (ANOVA). The differences between the study and the control groups in terms of age and sex were evaluated using the Independent t-test and the Fisher's Exact test, respectively. Post-hoc analysis of data was performed based on the Scheffe's test. Intraexaminer agreement of data was evaluated using Kappa statistics. In the present study $\mathrm{P}<0.05$ was considered to indicate statistical significance.

\section{Results}

The study group (IP) consisted of 45 boys and 35 girls with a mean age of 5.1 years, and the control group (WIP) consisted of 43 boys and 37 girls with a mean age of 5.4 years. There was no significant difference between the two groups in terms of age (Independent t-test, $p=0.24$ ) or sex (Fisher's Exact test, $p=0.48$ ). No adverse events were observed during the course of the study.

Table 1. SEM scale for the assessment of children's behavior.

\begin{tabular}{|l|l|l|l|l|}
\hline Parameter & Comfort & Mild Discomfort & Moderate Discomfort & Severe Discomfort \\
\hline Sound & No sound. & $\begin{array}{l}\text { Non-specific sound } \\
\text { (probable pain). }\end{array}$ & $\begin{array}{l}\text { Verbal complaint, } \\
\text { louder sound. }\end{array}$ & $\begin{array}{l}\text { Verbal complaint, } \\
\text { shouting, crying. }\end{array}$ \\
\hline Eye & No sign. & $\begin{array}{l}\text { Dilated eyes without } \\
\text { tears (anxiety sign). }\end{array}$ & $\begin{array}{l}\text { Tears, sudden eye } \\
\text { movements. }\end{array}$ & $\begin{array}{l}\text { Crying, tears } \\
\text { covering the face. }\end{array}$ \\
\hline Motor & $\begin{array}{l}\text { Relaxed } \\
\text { body and } \\
\text { hand status. }\end{array}$ & $\begin{array}{l}\text { Muscular contraction, } \\
\text { contraction of hands. }\end{array}$ & $\begin{array}{l}\text { Sudden body and hand } \\
\text { movements. }\end{array}$ & $\begin{array}{l}\text { Hand movements, for } \\
\text { defense, turning the } \\
\text { head to the opposite } \\
\text { side. }\end{array}$ \\
\hline
\end{tabular}


Table 2. SEM values for the experimental groups.

\begin{tabular}{|l|c|c|c|c|}
\hline \multicolumn{1}{|c|}{ Group } & Sound & Eye & Motor & Sum \\
\hline $\begin{array}{l}\text { Ice Pre-treatment } \\
(n=80)\end{array}$ & 1.15 & 1.50 & 1.76 & 4.41 \\
\hline $\begin{array}{l}\text { No Ice Pre-treatment } \\
(n=80)\end{array}$ & 2.54 & 3.25 & 2.78 & 8.57 \\
\hline
\end{tabular}

Intra-examiner Agreement of Data

The Kappa statistics for intra-examiner agreement for the SEM data was found to be excellent $(r=0.88)$.

\section{Univariate Analysis of SEM}

The SEM scale findings are presented in Table 2. A painful reaction according to the SEM scale (grade 4) for all three components (sound, eye, and motor) was reported in the WIP group. No severe pain reaction was observed in the IP group. There were no significant within-group differences between the values for the sound, eye, and motor components for either the WIP or IP groups $(P>0.05)$.

\section{Multivariate Analysis of the SEM}

The difference between the WIP and IP groups was statistically significant $(P<0.05)$. All three components of the SEM in the IP group were consistently lower than the WIP group. Moreover, the SEM value for the WIP group surpassed that of the IP group $(P<0.05)$.

\section{Discussion}

The aim of the study was to evaluate the effect of cooling the soft tissue of injection sites on the pain perceptions of pediatric patients during the administration of local anesthesia for routine dental procedures.

The results of the present study showed cooling of the injection site for a nerve block at $0^{\circ} \mathrm{C}$ for 2 minutes prior to the injection of local anesthetic agent did significantly reduce the pain perceived during administration of local anesthesia for routine dental procedures.

These findings are consistent with those reported for skin cooling in studies involving laser therapy and inguinal hernia repair. Chan et al. ${ }^{25}$ used a laser system with a cooling device to treat 37 patients who had a nevus of Ota removed. They reported patients perceived less pain on the side where cooling was employed. However, the aforementioned study did not elaborate on the objective criteria used to assess pain. Moreover, the pain induced by laser therapy may be quite distinct from that caused by local anesthetic infiltration. Leff et al ${ }^{38}$ reported the cooling of the injection site for a nerve block 5 minutes prior to the administration of local anesthetic agent in patients undergoing inguinal hernia repair significantly reduces the pain perceived during the injection. The results of the present study are in accordance with those of Harbert ${ }^{36}$ who used topical ice to reduce pain perception associated with palatal injections. Moreover, Goel et al. ${ }^{33}$ used ice cubes as a cryoanalgesic preparation before the administration of local anesthetic for eyelid surgery which resulted in a significant reduction in injection pain. Kuwahara and Skinner ${ }^{39}$ also reported the distress caused by lidocaine and epinephrine injection was reduced by using ice application.

A number of theories have been put forward to explain the mechanism by which ice pretreatment reduces the effects of injury and induces analgesia at a local level. These include reduction of tissue metabolism and vasoconstriction, thereby, reducing the inflow of inflammatory mediators and decreasing edema. This may explain the successful application of topical cooling to reduce bruising, bleeding, and edema in sports injuries and after orthopedic surgery. ${ }^{40-44}$

Local cooling is also believed to slow or eliminate pain signal transmission. ${ }^{45}$ Free nerve endings 


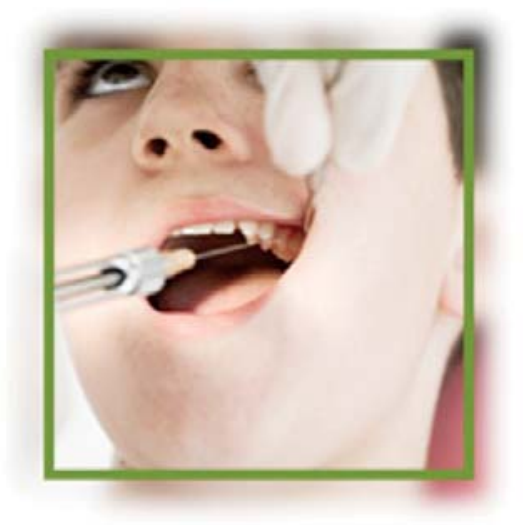

abound and terminate in all layers of the mucosa, including the epithelium. The effect of cold is to slow the velocity of nerve impulse conduction. Although different types of nerve fibers conduct at different speeds, they experience a proportional decrease in velocity for each degree drop in temperature, ceasing completely in the range of $10^{\circ} \mathrm{C}$ to $0^{\circ} \mathrm{C} .^{8}$

Low temperatures have been observed to retard neuromuscular transmission ${ }^{46}$ and cooling muscle tissue reduces its tone via a reduction in activity of the muscle spindles. ${ }^{47}$ Topical cold application stimulates myelinated A- $\sigma$ fibers, activating inhibitory pain pathways, which in turn raises the pain threshold. Cold has also been demonstrated to work at the spinal level to inhibit the stretch reflex and reduce muscle spasm. ${ }^{45}$
The results of the present study support the notion topical cooling raises the pain threshold to noxious stimuli such as the penetration of the needle during the injection of local anesthetic agents.

However, there were limitations in this study. The discomfort from ice contact is time dependent and the threshold is very subjective. Recommendations for a waiting time to allow for topical anesthetic penetration vary from 2 to 5 minutes. The 5 -minute duration of this procedure is well accepted by apprehensive adults and teenagers, but it is less readily tolerated by restless children. ${ }^{38} \mathrm{~A} 2$-minute contact duration of the ice cube used in this study was determined to be optimal based on our preliminary study.

\section{Conclusion}

The results of this study showed cooling of the injection site of a nerve block prior to the administration of local anesthesia significantly reduced the pain perceived by pediatric patients. The technique is comfortable, safe, and physiologically effective.

\section{Clinical Significance}

Pre-cooling of the soft tissues of an injection site prior to the administration of a local anesthetic can minimize the discomfort of the injection procedure and facilitate the management of pediatric patients during this phase of a dental procedure. 


\section{References}

1. Nuttall NM, Bradnock G, White D, Morris J, Nunn J. Dental attendance in 1998 and implications for the future. Br Dent J. 2001; 190:177-82.

2. Fiset L, Milgrom P, Weinstein P, Getz T, Glassman P. Psychophysiological responses to dental injections. J Am Dent Assoc. 1985; 111:578-82.

3. Marks I. Blood-injury phobia: a review. Am J Psychiatry. 1988; 145:207-13.

4. Ost LG. Acquisition of blood and injection phobia and anxiety response patterns in clinical patients. Behav Res Ther. 1991; 29:323-32.

5. Grassick P. The fear behind the fear: a case study of apparent simple injection phobia. J Behav Ther Exp Psychiatry. 1990; 21:281-7.

6. Mathewson RJ, Primosch RE. Fundamentals of Pediatric Dentistry. Quintessence. 3rd ed. 1995. p 163.

7. O'Brien L, Taddio A, Lyszkiewicz DA, Koren G. A critical review of the topical local anesthetic amethocaine (Ametop) for pediatric pain. Paediatr Drugs. 2005; 7:41-54.

8. Touyz LZ, Lamontagne P, Smith BE. Pain and anxiety reduction using a manual stimulation distraction device when administering local analgesia oro-dental injections: a multi-center clinical investigation. J Clin Dent. 2004; 15:88-92.

9. Ong EL, Lim NL, Koay CK. Towards a pain-free venepuncture. Anaesthesia. 2000; 55:260-2.

10. Colaric KB, Overton DT, Moore K. Pain reduction in lidocaine administration through buffering and warming. Am J Emerg Med. 1998; 16:353-6.

11. Scarfone RJ, Jasani M, Gracely EJ. Pain of local anesthetics: rate of administration and buffering. Ann Emerg Med. 1998; 31:36-40.

12. Bartfield JM, Crisafulli KM, Raccio-Robak N, Salluzzo RF. The effects of warming and buffering on pain of infiltration of lidocaine. Acad Emerg Med. 1995; 2:254-8.

13. Courtney DJ, Agrawal S, Revington PJ. Local anaesthesia: to warm or alter the $\mathrm{pH}$ ? A survey of current practice. J R Coll Surg Edinb. 1999; 44:167-71.

14. Younis I, Bhutiani RP. Taking the 'ouch' out - effect of buffering commercial xylocaine on infiltration and procedure pain - a prospective, randomised, double-blind, controlled trial. Ann R Coll Surg Engl. 2004; 86:213-7.

15. Orlinsky M, Hudson C, Chan L, Deslauriers R. Pain comparison of unbuffered versus buffered lidocaine in local wound infiltration. J Emerg Med. 1992; 10:411-5.

16. Masters JE. Randomised control trial of $\mathrm{pH}$ buffered lignocaine with adrenaline in outpatient operations. Br J Plast Surg. 1998: 51:385-7.

17. Fitton AR, Ragbir M, Milling MA. The use of $\mathrm{pH}$ adjusted lignocaine in controlling operative pain in the day surgery unit: a prospective, randomised trial. Br J Plast Surg. 1996; 49:404-8.

18. McMaster WC. A literary review on ice therapy in injuries. Am J Sports Med. 1977; 5:124-6.

19. Meeusen R, Lievens P. The use of cryotherapy in sports injuries. Sports Med. 1986; 3:398-414.

20. Brandner B, Munro B, Bromby LM, Hetreed M. Evaluation of the contribution to postoperative analgesia by local cooling of the wound. Anaesthesia. 1996; 51:1021-5.

21. Saito N, Horiuchi H, Kobayashi S, Nawata M, Takaoka K. Continuous local cooling for pain relief following total hip arthroplasty. J Arthroplasty. 2004; 19:334-7.

22. Daniel DM, Stone ML, Arendt DL. The effect of cold therapy on pain, swelling, and range of motion after anterior cruciate ligament reconstructive surgery. Arthroscopy. 1994; 10:530-3.

23. Ohkoshi Y, Ohkoshi M, Nagasaki S. The effect of cryotherapy on intraarticular temperature and postoperative care after anterior cruciate ligament reconstruction. Am J Sports Med. 1999; 27:357-62.

24. Brandsson S, Rydgren B, Hedner T, Eriksson BI, Lundin O, Swärd L, Karlsson J. Postoperative analgesic effects of an external cooling system and intraarticular bupivacaine/morphine after arthroscopic cruciate ligament surgery. Knee Surg Sports Traumatol Arthrosc. 1996; 4:200-5.

25. Chan HH, Lam LK, Wong DS, Wei WI. Role of skin cooling in improving patient tolerability of Q-switched Alexandrite (QS Alex) laser in nevus of Ota treatment. Lasers Surg Med. 2003; 32:148-51. 
26. Russell SC, Doyle E. A risk-benefit assessment of topical percutaneous local anaesthetics in children. Drug Saf. 1997; 16:279-287.

27. Meeusen R, Lievens P. The use of cryotherapy in sports injuries. Sports Med. 1986; 3:398-414.

28. Waibel KH, Katial RK. Effect of topical vapocoolant spray on skin test wheal, flare, and pain responses. Ann Allergy Asthma Immunol. 2005; 5:149-153.

29. Lacour M, Le Coultre C. Spray-induced frostbite in a child: a new hazard with novel aerosol propellants. Pediatr Dermatol. 1991; 8:207-209.

30. Aberer W. Local anaesthesia with ethyl chloride freezing: problems despite proper application. Br J Dermatol. 1991; 124:113-114.

31. Broussard LA, Broussard AK, Pittman TS, Lirette DK. Death due to inhalation of ethyl chloride. J Forensic Sci. 2000; 45:223-225.

32. Ernst E, Fialka V. Ice freezes pain? A review of the clinical effectiveness of analgesic cold therapy. J Pain Symptom Manage. 1994; 9:56-59.

33. Goel S, Chang B, Bhan K, El-Hindy N, Kolli S. "Cryoanalgesic preparation" before local anaesthetic injection for lid surgery. Orbit. 2006; 25:107-110.

34. van der Westhuijzen AJ, Becker PJ, Morkel J, Roelse JA. A randomized observer blind comparison of bilateral facial ice pack therapy with no ice therapy following third molar surgery. Int $\mathrm{J}$ Oral Maxillofac Surg. 2005; 34:281-286.

35. Hubbard TJ, Denegar CR. Does cryotherapy improve outcomes with soft tissue injury? J Athl Train. 2004; 39:278-279.

36. Harbert H. Topical ice: a precursor to palatal injections. J Endod. 1989; 15:27-8.

37. Yoon WY, Chung SP, Lee HS, Park YS. Analgesic pretreatment for antibiotic skin test: vapocoolant spray vs ice cube. Am J Emerg Med. 2008; 26:59-61.

38. Leff DR, Nortley M, Van Dang, Bhutiani RP. The effect of local cooling on pain perception during infiltration of local anaesthetic agents, a prospective randomised controlled trial. J Anaesth. 2007; 62:677-682.

39. Kuwahara RT, Skinner RB. EMLA versus ice as a topical anesthetic. Dermatol Surg. 2001; 27:495-496.

40. McMaster WC. A literary review on ice therapy in injuries. Am J Sports Med. 1977; 5:124-6.

41. Meeusen R, Lievens P. The use of cryotherapy in sports injuries. Sports Med. 1986; 3:398-414.

42. Brandner B, Munro B, Bromby LM, Hetreed M. Evaluation of the contribution to postoperative analgesia by local cooling of the wound. Anaesthesia. 1996; 51:1021-5.

43. Saito N, Horiuchi H, Kobayashi S, Nawata M, Takaoka K. Continuous local cooling for pain relief following total hip arthroplasty. J Arthroplasty. 2004; 19:334-7.

44. Ohkoshi Y, Ohkoshi M, Nagasaki S. The effect of cryotherapy on intraarticular temperature and postoperative care after anterior cruciate ligament reconstruction. Am J Sports Med. 1999; 27:357-62.

45. Abramson DI, Chu LS, Tuck S Jr, Lee SW, Richardson G, Levin M. Effect of tissue temperatures and blood flow on motor nerve conduction velocity. JAMA. 1966; 198:1082-8.

46. Halar EM, DeLisa JA, Brozovich FV. Nerve conduction velocity: relationship of skin, subcutaneous and intramuscular temperatures. Arch Phys Med Rehabil. 1980; 61:199-203.

47. Ottoson D. The effects of temperature on the isolated muscle spindle. J Physiol. 1965; 180:636-48.

\section{About the Authors}

Naser AsI Aminabadi, DDS, MSc

Dr. Aminabadi is a Professor in the Department of Pedodontics of the School of Dentistry at Tabriz University of Medical Sciences in Tabriz, East Azerbaijan, Iran. His research field includes behavioral management of children, orthodontic correction of dentoskeletal anomalies, and root canal therapy of primary teeth.

e-mail: aslaminabadi@gmail.com 
Ramain Mostofi Zadeh Farahani, DDS

Dr. Farahani is a Research Assistant in the Department of Pedodontics of the School of Dentistry at Tabriz University of Medical Sciences in Tabriz, East Azerbaijan, Iran. His primary research interests include wound healing and tissue regeneration in addition to his interest in the field of pediatric dentistry.

e-mail: r.mostofi@gmail.com 